\title{
Isotope effects in mechanistic studies of L-tyrosine halogen derivatives hydroxylation catalyzed by tyrosinase
}

\author{
Małgorzata Pająk ${ }^{1}$ Marianna Kańska ${ }^{2}$
}

Received: 23 August 2017/Published online: 23 October 2017

(c) The Author(s) 2017. This article is an open access publication

\begin{abstract}
The kinetic (KIE) and solvent (SIE) isotope effect methods were used to investigate the mechanism of enzymatic hydroxylation of halogenated derivatives of $\mathrm{L}$ tyrosine to L-DOPA catalyzed by the enzyme tyrosinase (EC 1.14.18.1). The values of deuterium KIE and SIE were obtained using the non-competitive method with spectrophotometric measurements. The Lineweaver-Burk plots were used for determination of the inhibition mode of $3^{\prime}$ iodo-L-tyrosine. Based upon kinetic effects values the mechanism of action of enzyme tyrosinase was proposed.
\end{abstract}

Keywords Deuterium - Halogenated derivatives of Ltyrosine $\cdot$ Isotope effects - Tyrosinase

\section{Introduction}

The enzyme tyrosinase (EC 1.14.18.1) is a copper-containing monooxygenase widely distributed in nature $[1,2]$. It is responsible for melanization in animals and enzymatic browning of mushroom, fruit and vegetables in the presence of air. This enzyme catalyses the hydroxylation of monophenol in the ortho position (cresolase activity) and

Małgorzata Pająk

mpajak@chem.uw.edu.pl

1 Department of Chemistry, Warsaw University, Pasteur 1 Str., 02-093 Warsaw, Poland

2 Department of Biochemistry, 2nd Faculty of Medicine, Medical University of Warsaw, 61 Zwirki i Wigury Av., 02-091 Warsaw, Poland oxidation of resulting diphenol to $o$-quinone (catalase activity). Tyrosinase is involved into L-tyrosine (L-Tyr) metabolic pathway where it catalyses hydroxylation of $\mathrm{L}^{-}$ Tyr to L-DOPA $\left(3^{\prime}, 4^{\prime}\right.$-dihydroxy-L-phenylalaniane $)$ - the first step of neurotransmitters formation, and oxidation of L-DOPA to dopaquinone $\left(3^{\prime}, 4^{\prime}\right.$-dioxy-L-phenylalanine $)$ the precursor in melanin formation (Fig. 1). The disturbed metabolism of L-Tyr leads to many diseases including albinism, vitiligo, melanoma or Parkinson's disease [3-6].

Halogenated derivatives of L-Tyr, labeled with shortlived radioisotopes, have been recently applied in nuclear medicine for diagnosis and treatment of numerous diseases. $2^{\prime}-\left[{ }^{18} \mathrm{~F}\right]$ Fluoro-L-Tyr and $6{ }^{\prime}-\left[{ }^{18} \mathrm{~F}\right]$ Fluoro-L- $m$-Tyr are used in positron emission tomography (PET) for measurement of cerebral protein synthesis and to study the dopaminergic system in humans [7, 8]. $2^{\prime}-\left[{ }^{123} \mathrm{I}\right]$ Iodo- and $3^{\prime}-\left[{ }^{125} \mathrm{I}\right]$ iodo- $\alpha-$ methyl-L-Tyr are developed as tumor imaging agents [9, 10] for single photon emission computed tomography (SPECT). Thus, from medical point of view it is necessary to investigate the metabolism of L-Tyr halogenated derivatives before using such kind of pharmaceuticals in SPECT or PET diagnostics. It is known that iodinated derivatives of L-Tyr are inhibitors of tyrosine hydroxylase (1.14.16.2), the iron-containing monooxygenase which also catalyses hydroxylation of L-Tyr to L-DOPA [11-13]. Therefore, the aim of our studies is to investigate the influence of halogen substitution on enzymatic conversion kinetics of L-Tyr to L-DOPA using kinetic (KIE) and solvent (SIE) isotope effects method. The numerical values of deuterium KIE's and SIE's allow to designate the rate determining step and characterize many details of the mechanism of investigated reaction $[14,15]$. 


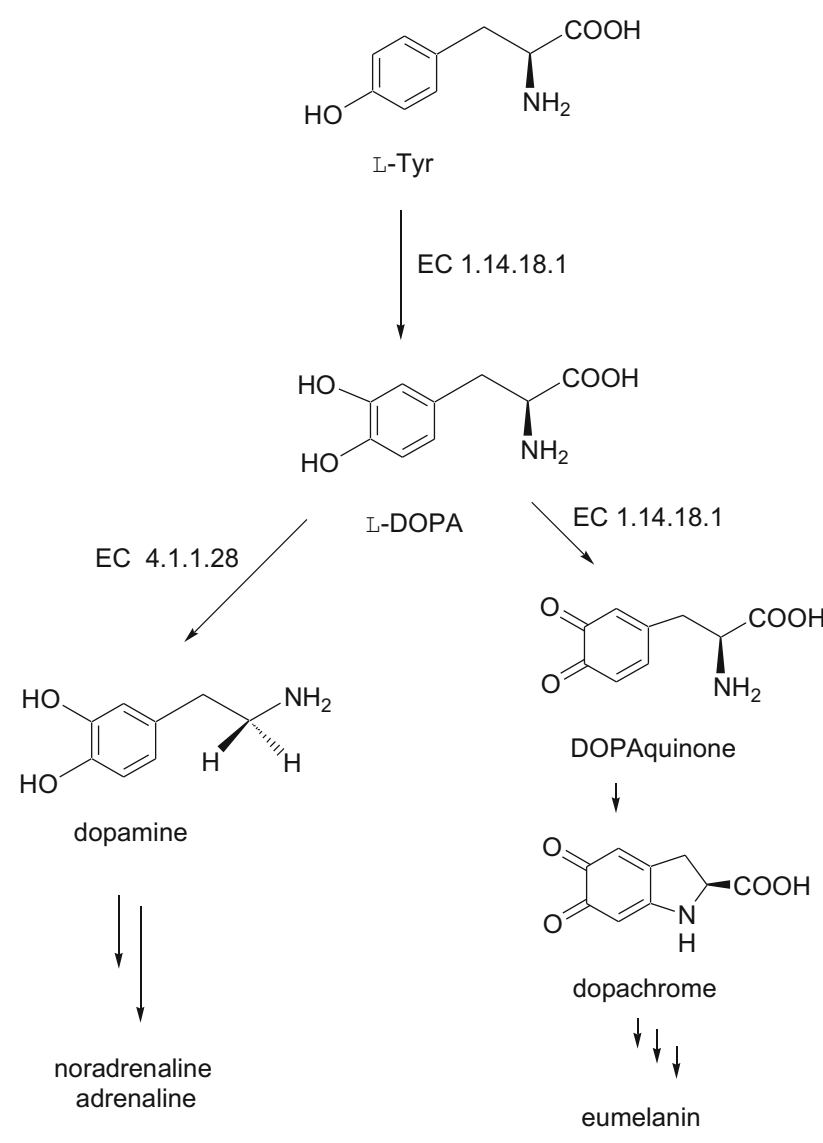

Fig. 1 The fragment of L-Tyr metabolic pathway

\section{Experimental}

\section{Materials}

The enzyme mushroom tyrosinase (EC 1.14.18.1, $1715 \mathrm{U} /$ $\mathrm{mg}$ ) and 3'-iodo-L-tyrosine were from Sigma. Deuterated water $\left(99.9 \%\right.$ D) and Amberlite IR-120 $\left(\mathrm{Na}^{+}\right)$resin were from Aldrich. Silica gel plates (silica gel $60 \mathrm{~F}_{254}$ ) were purchased from Merck. Deuterated $30 \% \mathrm{KO}^{2} \mathrm{H} /{ }^{2} \mathrm{H}_{2} \mathrm{O}$ and $85 \%{ }^{2} \mathrm{H}_{3} \mathrm{PO}_{4} /{ }^{2} \mathrm{H}_{2} \mathrm{O}$ were obtained from POLATOM, Poland. $3^{\prime}$-Fluoro-L-tyrosine and $3^{\prime}$-chloro-L-tyrosine were purchased from Alfa Aesar.

\section{Methods}

The proton NMR spectra were recorded in $\mathrm{D}_{2} \mathrm{O}$ using tetramethylsilane (TMS) as internal standard on Varian $500 \mathrm{MHz}$ Unity-Plus spectrometer. Chemical shifts are reported in ppm in the following format: chemical shifts, multiplicity ( $\mathrm{s}=$ singlet, $\mathrm{d}=$ doublet, $\mathrm{t}=$ triplet, $q=$ quartet), type of hydrogen. In the course of column chromatographic separation the presence of products was checked by TLC using silica gel plates and acetonitrile:water $(4: 1 ; \mathrm{v} / \mathrm{v})$ developing solvent (visualization by $0.1 \%$ ethanol solution of ninhydrin).

The kinetic assays were performed using Shimadzu-UV1800 spectrophotometer in plastic UV-cuvette micro (BRAND, Germany).

Synthesis of $3^{\prime}$-fluoro- $\left[5^{\prime}{ }^{2} H\right]-, 1$ and $3^{\prime}$-chloro- $\left[5^{\prime}{ }^{2} H\right]-L^{-}$ Tyr, 2

$20 \mathrm{mg}(0.1 \mathrm{mM})$ of $3^{\prime}$-fluoro-L-Tyr or $20 \mathrm{mg}(0.09 \mathrm{mM})$ of $3^{\prime}$-chloro-L-Tyr was dissolved in $2 \mathrm{~mL}$ of $6 \mathrm{M} \mathrm{DCl} / \mathrm{D}_{2} \mathrm{O}$ and placed in glass ampoules. The ampoules were connected to a vacuum apparatus, their contents were frozen with liquid nitrogen, outgassed and sealed under vacuum. After thawing, ampoules were placed in a thermostat and kept for $24 \mathrm{~h}$ at $120{ }^{\circ} \mathrm{C}$. Next, the residues were lyophilized, dissolved in $2 \mathrm{~mL}$ of water and loaded onto a chromatographic column $(100 \times 10 \mathrm{~mm})$ filled with ionexchange resin Amberlite IR-120 $\left(\mathrm{H}^{+}\right)$and deuterium from labile positions was washed out with water. Then products were eluted with $1 \mathrm{M} \mathrm{NH}_{3}$ (aq.). The presence of products in each fraction was checked by TLC. The fractions containing products were combined and lyophilized, leaving $11.6 \mathrm{mg}(0.057 \mathrm{mmol})$ of 1 and $14.1 \mathrm{mg}(0.065 \mathrm{mmol})$ of 2 with chemical yields 58 and $70 \%$, respectively.

${ }^{1} \mathrm{H}$ NMR $\left(\mathrm{D}_{2} \mathrm{O}, \delta \mathrm{ppm}\right)$ :

3'-fluoro-L-Tyr: 7.06 , dd, $1 \mathrm{H}_{2^{\prime}} ; 6.99, \mathrm{~s}, 1 \mathrm{H}_{5^{\prime}} ; 6.96$, t, $1 \mathrm{H}_{6^{\prime}} ; 3.90, \mathrm{q}, 1 \mathrm{H} \alpha, 3.10, \mathrm{dq}, 2 \mathrm{H}_{\beta}$, $3^{\prime}$-fluoro-[5'- $\left.{ }^{2} \mathrm{H}\right]$-L-Tyr, 1: 7.09, d, $1 \mathrm{H}_{2^{\prime}} ; 6.97, \mathrm{~s}, 1 \mathrm{H}_{6^{\prime}} ; 4.24$, t, $1 \mathrm{H}_{\alpha} ; 3.20, \mathrm{dq}, 2 \mathrm{H}_{\beta}$, $3^{\prime}$-chloro-L-Tyr: 7.30, d, $1 \mathrm{H}_{2^{\prime}} ; 7.09$, dd, $1 \mathrm{H}_{6^{\prime}} ; 6.97, \mathrm{~d}, 1 \mathrm{H}_{5^{\prime}}$; 3.91, q, $1 \mathrm{H}_{\alpha} ; 3.09$, dq, $2 \mathrm{H}_{\beta}$, $3^{\prime}$-chloro-[ $\left[5^{\prime}{ }^{2} \mathrm{H}\right]$-L-Tyr, 2: 7.25, s, $1 \mathrm{H}_{2^{\prime}} ; 7.06, \mathrm{~s}, 1 \mathrm{H}_{6^{\prime}} ; 4.23$, t, $1 \mathrm{H}_{\alpha} ; 3.15, \mathrm{dq}, 2 \mathrm{H}_{\beta}$.

Determination of H/D KIE for $3^{\prime}$-fluoro- $\left[5^{\prime}-{ }^{2} H\right]-L-T y r$ and $3^{\prime}$-chloro- $\left[5^{\prime}{ }_{-}^{2} H\right]-L-T y r$

The solutions of $3^{\prime}$-fluoro-[ $\left[5^{\prime}-{ }_{-}^{2} \mathrm{H}\right]-, 3^{\prime}$-chloro- $\left[5^{\prime}{ }_{-}^{2} \mathrm{H}\right]-\mathrm{L}-\mathrm{Tyr}$ and enzyme tyrosinase were prepared in $0.1 \mathrm{M}$ phosphate buffer, $\mathrm{pH}$ 6.8. Each kinetic experiment consisted of six runs carried out at room temperature in $750 \mu \mathrm{L}$ plastic cuvette for different concentration of halogenated derivative of L-Tyr (in $0.2-1.2 \mathrm{mM}$ range with 0.2 intervals). The reaction was started by adding to each cuvette $10 \mu \mathrm{L}$ $(17.15 \mathrm{U})$ solution of enzyme tyrosinase. The progress of hydroxylation was registered spectrophotometrically at $\lambda_{\max }=475 \mathrm{~nm}$ for $20 \mathrm{~min}$ ( $1 \mathrm{~min}$ interval). The increasing absorbance was measured as a result of dopachrome formation. Then, the reaction rates were calculated from the obtained experimental values for different concentration of halogenated L-Tyr and used for the optimization of 
kinetic parameters $\left(V_{\max }\right.$ and $\left.K_{\mathrm{m}}\right)$ in the Michaelis-Menten equation.

Determination of SIE for 3'-fluoro- and 3'-chloro-L-Tyr was carried out the similar way as described above. Each kinetic experiment consisted of six runs carried out at room temperature in protonated and deuterated ( $\mathrm{pD}$ 7.2) media separately. The SIEs were obtained by dividing the values of $V_{\max }$ and $V_{\max } / K_{\mathrm{m}}$ for the reaction carried out in water and fully deuterated medium.

\section{Determination of tyrosinase inhibition by $3^{\prime}$-iodo-L-Tyr}

Each kinetic experiment consisted of six runs carried out at room temperature in $750 \mu \mathrm{L}$ plastic cuvette for different concentration of L-Tyr (in $0.2-1.2 \mathrm{mM}$ range with 0.2 intervals) in $0.1 \mathrm{M}$ phosphate buffer, $\mathrm{pH}$ 6.8. To each cuvette the same amount of $3^{\prime}$-iodo-L-Tyr was added (1, 2 or $3 \mathrm{mM}$, depending on the experimental series). The reaction was started by adding $10 \mu \mathrm{L}(17.15 \mathrm{U})$ solution of enzyme tyrosinase. The increasing absorbance was measured spectrophotometrically at $\lambda_{\max }=475 \mathrm{~nm}$ for $20 \mathrm{~min}$ (1 min interval) as a result of dopachrome formation. Then, the kinetic parameters $\left(V_{\max }\right.$ and $K_{\mathrm{m}}$ ) were calculated and inhibition constants were determined.

\section{Results and discussion}

\section{Synthesis of $3^{\prime}$-fluoro-[5 $\left.5^{\prime}-{ }^{2} H\right]-, 1$ and $3^{\prime}$-chloro- $\left[5^{\prime}-{ }^{2} \mathbf{H}\right]-\mathrm{L}-\mathrm{Tyr}, 2$}

The deuteration of halogenated derivatives of L-Tyr in aromatic ring was carried out in $6 \mathrm{M} \mathrm{DCl} / \mathrm{D}_{2} \mathrm{O}$ at elevated temperature according to procedure described by us earlier [16] (Fig. 2).

The structure and degree of deuterium incorporation was checked by ${ }^{1} \mathrm{H}$ NMR spectroscopy and calculated on the basis of signals integration of authentic and deuterated compounds. Disappearance of signals of protons at $5^{\prime}$ position indicates that deuterium enrichment reached almost $100 \%$ at the $5^{\prime}$-position of compounds $\mathbf{1}$ and $\mathbf{2}$ aromatic rings.

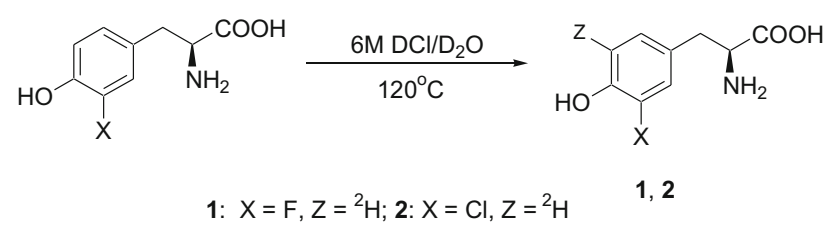

Fig. 2 Synthesis of halogenated derivatives of L-Tyr labeled with deuterium in aromatic ring

\section{Determination of isotope effects}

The kinetic parameters needed for calculation of deuterium isotope effects i.e., $V_{\max }$ and $K_{\mathrm{m}}$ for the reaction of hydroxylation of L-Tyr to L-DOPA (Fig. 1) were determined using non-competitive spectrophotometric method [17]. The values of isotope effects were determined from initial rates (v) and calculated using computer software Enzfitter 1.05 according to Michaelis [Eq. (1)]

$K_{m}=S\left(\frac{V_{\max }}{v}-1\right)$

where $v$ is the reaction rate at substrate concentration $S$, $V_{\max }$ is maximum velocity and $K_{\mathrm{m}}$ is Michaelis-Menten constant. The experimental errors were calculated using Student's t-distribution for $95 \%$ confidence interval.

Calculated values of isotope effects are presented in Table 1. Obtained values of KIEs (greater than unity) indicate that the hydrogen atoms in the position C-3 and $\mathrm{C}-5$ of the aromatic ring of halogenated L-Tyr play a role in the conversion of the "enzyme-substrate" complex into "enzyme-product" complex. During the hydroxylation the phenolic substrate coordinates to oxytyrosinase (Fig. 3). In the first step there is the nucleophilic attack of the hydroxyl group of L-Tyr on the copper ion with proton transfer from the $\mathrm{OH}$ group of $\mathrm{C}-4$ to the peroxide bound to the copper atom in oxytyrosinase. In the second step electrophilic attack of the peroxide at the $\mathrm{C}-3$ position of L-Tyr is observed [18-20]. The numerical values of KIEs obtained for L-Tyr [20] were greater than or close to 2, which may suggest, that halides donate electron density and hinder the formation of $\mathrm{C}-\mathrm{O}$ bond, which indicates that this is the rate determining step of investigated reaction (not $\mathrm{C}-\mathrm{H}$ bond breaking as in case of L-Tyr). That confirms the complexity of this process. SIEs values indicate that solvent have an influence on the proton transfer occurring in this reaction, what is postulated in the literature [21].

\section{Determination of tyrosinase inhibition by $3^{\prime}$-iodo-L- Tyr}

We have investigated the inhibitory effect of $3^{\prime}$-iodo-L-Tyr on the hydroxylation of L-Tyr to L-DOPA catalysed by tyrosinase. The type of inhibition was determined from Lineweaver-Burk plots (Fig. 4).

The Lineweaver-Burk plots showed changes in both $V_{\max }$ and $K_{\mathrm{m}}$ parameters. The value of $V_{\max }$ decreases with increasing amount of inhibitor while $K_{\mathrm{m}}$ parameter increases (Table 2) which indicates that $3^{\prime}$-iodo-L-Tyr induced mixed type of inhibition with competitive inhibition constant $K_{\mathrm{i}}=5.6 \pm 0.9 \mathrm{mM}$ and non-competitive inhibition constant $K_{\mathrm{i}}^{\prime}=3.3 \pm 0.9 \mathrm{mM}$, calculated from the Eqs. (2) and (3). 
Table 1 KIE and SIE values for hydroxylation of halogenated derivatives of L-Tyr

Fig. 3 Proposed mechanism for action of tyrosinase [20]

\begin{tabular}{lcc}
\hline Compound & KIE on $V_{\max }$ & KIE on $V_{\max } / K_{\mathrm{m}}$ \\
\hline${\left.\text { 3'-Fluoro-L-Tyr/3'-fluoro-[5'- }{ }^{2} \mathrm{H}\right] \text {-L-Tyr }}^{\prime}$ & $1.34 \pm 0.10$ & $1.65 \pm 0.10$ \\
3'-Chloro-L-Tyr/3'-chloro-[5 $\left.{ }^{\prime}{ }^{2} \mathrm{H}\right]$-L-Tyr & $1.34 \pm 0.07$ & $1.49 \pm 0.08$ \\
\hline Compound & SIE on $V_{\max }$ & SIE on $V_{\max } / K_{\mathrm{m}}$ \\
\hline 3'-Fluoro-L-Tyr & $2.93 \pm 0.22$ & $1.84 \pm 0.14$ \\
3'-Chloro-L-Tyr & $1.70 \pm 0.09$ & $1.31 \pm 0.06$ \\
\hline
\end{tabular}

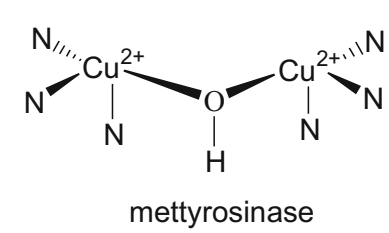

oxytyrosinase

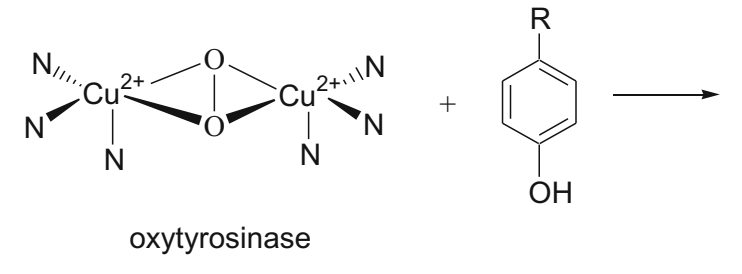

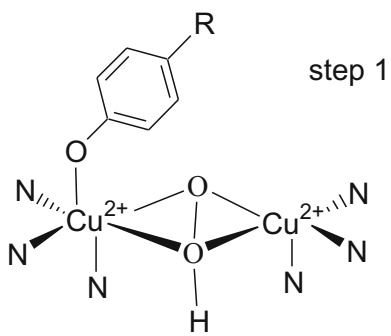

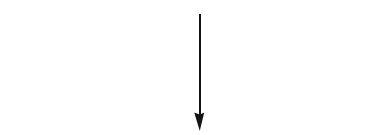<smiles>[R]c1ccc2c(c1)O[Ge](N)(N)C(N)(N)OC(N)(N)O2</smiles>
step 2 $\mathrm{N}$<smiles>C=C</smiles>

1




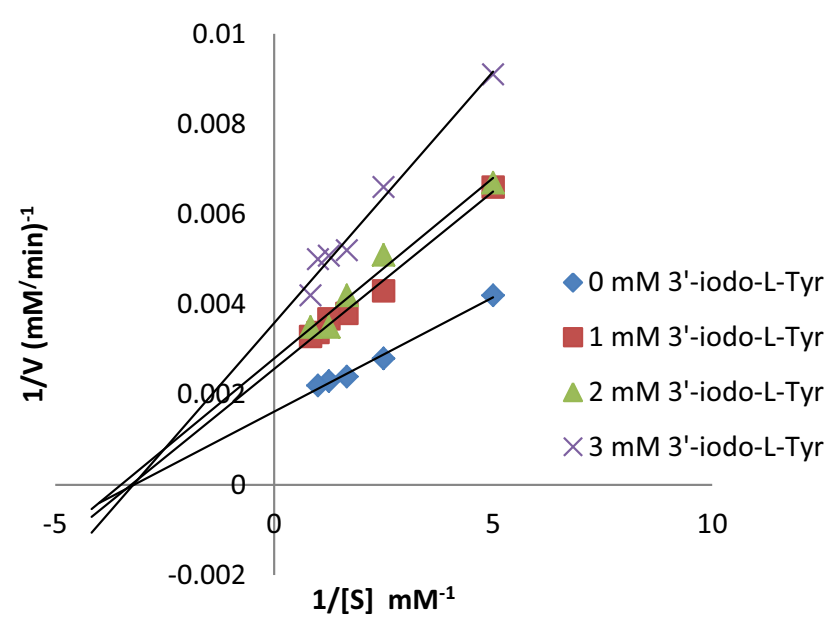

Fig. 4 Determination of inhibition type of $3^{\prime}$-iodo-L-Tyr by Lineweaver-Burk plot

Table 2 Values of kinetic parameters for hydroxylation of L-Tyr in presence of $3^{\prime}$-iodo-L-Tyr

\begin{tabular}{lll}
\hline Compound & $V_{\max }\left(\mathrm{mM} \times \mathrm{min}^{-1}\right)$ & $K_{\mathrm{m}}(\mathrm{mM})$ \\
\hline L-Tyr & $558 \pm 3$ & $0.24 \pm 0.02$ \\
L-Tyr/1 mM 3'-iodo-L-Tyr & $397 \pm 33$ & $0.28 \pm 0.05$ \\
L-Tyr/2 mM 3'-iodo-L-Tyr & $359 \pm 13$ & $0.32 \pm 0.03$ \\
L-Tyr/3 mM 3'-iodo-L-Tyr & $307 \pm 4$ & $0.39 \pm 0.01$ \\
\hline
\end{tabular}

3'-Iodo-L-Tyr may bond, not only with free enzyme, but also with enzyme-substrate complex. That type of inhibition of tyrosinase is known in literature for some carvacrol derivatives and terephthalic acid [22, 23].

\section{Conclusions}

The aim of this paper was to evaluate the influence of halogen substituent on the kinetics of L-Tyr hydroxylation catalyzed by tyrosinase. The KIE and SIE values obtained in this work are consistent with the mechanism of oxidation of phenolic compounds described earlier [20, 21] and confirms the complex mechanism of action of tyrosinase. Halides donate electron density and hinder the formation of $\mathrm{C}-\mathrm{O}$ bond during hydroxylation process. Deuterated solvent affect the proton transfer occurring in the first step of investigated reaction. $3^{\prime}$-Iodo-L-Tyr have been found to be an inhibitor of tyrosinase and induced mixed type of inhibition, that is, competitive and non-competitive ones.

Acknowledgements This work was financially supported by the Grant 501/86-DSM-102400.
Open Access This article is distributed under the terms of the Creative Commons Attribution 4.0 International License (http://crea tivecommons.org/licenses/by/4.0/), which permits unrestricted use, distribution, and reproduction in any medium, provided you give appropriate credit to the original author(s) and the source, provide a link to the Creative Commons license, and indicate if changes were made.

\section{References}

1. Hearing VJ, Ekel TM (1976) Mammalian tyrosinase. Biochem J 157:549-557

2. Garcia-Molina F, Hiner ANP, Fenoll LG, Rodriguez-Lopez JN, Garcia-Ruiz PA, Garcia-Canovas F, Tudela J (2005) Mushroom tyrosinase: catalase activity, inhibition, and suicide inactivation. J Agric Food Chem 53:3702-3709

3. Riley PA (1997) Molecules in focus. Melanin. Int J Biochem Cell Biol 29:1235-1239

4. Song YH (1997) Why tyrosinase for treatment of melanoma. Lancet 350:82-83

5. Oetting WS (2000) The tyrosinase gene and oculocutaneous albinism Type 1 (OCA1): a model for understanding the molecular biology of melanin formation. Pigment Cell Res $13: 320-325$

6. Thomas B (2009) Parkinson's disease: from molecular pathways in disease to therapeutic approaches. Antioxid Redox Signal 11:2077-2082

7. Castillo Melean J, Ermert J, Coenen HH (2011) Enantiospecific synthesis of $2-\left[{ }^{18} \mathrm{~F}\right]$ fluoro-L-phenylalanine and $2-\left[{ }^{18} \mathrm{~F}\right]$ fluoro-Ltyrosine by isotopic exchange. Org Biomol Chem 9:765-769

8. Asari S, Fujimoto K, Miyauchi A, Sato T, Nakano I, Muramatsu S (2011) Subregional 6- $\left[{ }^{18} \mathrm{~F}\right]$ fluoro-L- $m$-tyrosine uptake in the striatum in Parkinson's disease. BMC Neurol 11:35-40

9. Kersemans V, Cornelissen B, Kersemans K, Dierckx RA, De Spiegeleer B, Mertens J, Slegers G (2006) Comparative biodistribution study of the new tumor tracer $\left[{ }^{123} \mathrm{I}\right]-2$-iodo-L-phenylalanine with $\left[{ }^{123} \mathrm{I}\right]-2-$ iodo-L-tyrosine. Nucl Med Biol 33:111-117

10. Shikano N, Kanai Y, Kawai K, Ishikawa N, Endou H (2003) Characterization of 3-[ ${ }^{125}$ I] iodo- $\alpha$-methyl-L-tyrosine transport via human L-type amino acid transporter 1. Nucl Med Biol 30:31-37

11. Fitzpatric PF (1988) The $\mathrm{pH}$ dependence of binding of inhibitors to bovine adrenal tyrosine hydroxylase. J Biol Chem 263:16058-16062

12. Ness DK, Foley GL, Villar D, Hansen LG (1996) Effects of 3-iodo-L-tyrosine, a tyrosine hydroxylase inhibitor, on eye pigmentation and biogenic amines in the planarian, Dugesia dorotocephala. Fundam Appl Toxicol 30:153-161

13. Ito K, Yoshikawa M, Fujii T, Tabunoki H, Yokoyama T (2016) Melanin pigmentation gives rise to black spots on the wings of the silkworm Bombyx mori. J Insect Physiol 91-92:100-106

14. Northrop DB (1975) Steady-state analysis of kinetic isotope effects in enzymic reactions. Biochemistry 14:2644-2651

15. Schowen RL (2007) The use of solvent isotope effects in the pursuit of enzyme mechanisms. J Label Compd Radiopharm 50:1052-1062

16. Pająk M, Kańska M (2006) Synthesis of isotopomers of dopamine labeled with deuterium or tritium. J Label Compd Radiopharm 49:1061-1067

17. Parkin DW (1991) In: Cook PF (ed) Enzyme mechanism from isotope effects. CRS Press, Boca Raton, Boston, London

18. Winkler ME, Lerch K, Solomon EI (1981) Competitive inhibitor binding to the binuclear copper active site in tyrosinase. J Am Chem Soc 103:7001-7003 
19. Solomon EI, Sundaram UM, Machonkin TE (1996) Multicopper oxidases and oxygenases. Chem Rev 96:2563-2605

20. Kańska M, Dragulska S, Pająk M, Pałka K, Winnicka E (2015) Isotope effects in the hydroxylation of L-tyrosine catalyzed by tyrosinase. J Radioanal Nucl Chem 305:371-378

21. Fenoll LG, Penalver MJ, Rodriguez-Lopez JN, Garcia-Ruiz PA, Garcia-Canovas F, Tudela J (2004) Deuterium isotope effect on the oxidation of monophenols and $o$-diphenols by tyrosinase. Biochem J 380:643-650
22. Yin S-J, Si Y-X, Chen Y-F, Qian G-Y, Lü Z-R, Oh S, Lee J, Lee S, Yang J-M, Lee D-Y, Park Y-D (2011) Mixed type inhibition of tyrosinase from Agaricusbisporus by terephthalic acid: computational simulations and kinetics. Protein J 30:273-280

23. Ashraf Z, Rafiq M, Nadeem H, Hassan M, Afzal S, Waseem M, Afzal K, Latip J (2017) Carvacrol derivatives as mushroom tyrosinase inhibitors; synthesis, kinetics mechanism and molecular docking studies. PLoS ONE 12:e0178069 